\title{
Transcriptional Activator C Protein-mediated Unwinding of DNA as a Possible Mechanism for mom Gene Activation
}

\section{Shashwati Basak and Valakunja Nagaraja*}

Microbiology and Cell Biology Department, Indian Institute of Science, Bangalore 560012 India
The bacteriophage $\mathrm{Mu}$ mom gene encodes the unique DNA-modification function of the phage. Regulation of the mom gene at the transcriptional level is brought about by the transactivator protein $C$ of the phage. The mom promoter is an activator-dependent weak promoter having poor -10 and -35 elements separated by a 19 bp suboptimal spacer region. These features could constrain RNA polymerase occupancy at the promoter. Here, we have probed into the mechanism by which $\mathrm{C}$ protein acts as a transcriptional activator at $\mathrm{P}_{\text {mom }}$. In vivo dimethyl sulfate footprinting studies demonstrate $C$ protein-mediated asymmetric distortion of its specific site at the mom regulatory region. Using a coupled topoisomerase assay, we demonstrate that $C$ protein induces the unwinding of DNA. This C-mediated unwinding seems to be localised to the $3^{\prime}$ flanking region of the $C$ binding site located adjacent to and overlapping the -35 element of $\mathrm{P}_{\text {mom }}$. These results suggest that $\mathrm{C}$ protein-mediated torsional changes could be reorienting the -10 and -35 elements to a favorable conformation for RNA polymerase occupancy at the mom promoter.

(C) 1998 Academic Press

Keywords: bacteriophage $\mathrm{Mu}$; mom; C protein; DNA distortion

\section{Introduction}

Accurate initiation of transcription often requires interactions of the activator protein(s) with specific sequences and RNA polymerase (RNAP) in addition to the promoter-polymerase interactions (Raibaud \& Schwartz, 1984). This requirement for the mediation by activator proteins in the transcription activation process is a consequence of the promoter architecture. Activator proteins bind at various distances from the weak promoters to enhance binding or open-complex formation by RNAP (Busby \& Ebright, 1994). A large number of activator proteins have been identified in Escherichia coli itself and their mode of interaction has been studied (Collado-Vides et al., 1991; Ishihama, 1993). One would predict different transcription activation mechanisms to be operational considering the diversity of transcriptional activator proteins and their specific interactions. Apart from the protein-protein interactions between the activator and RNAP, protein-induced DNA distortion also

Abbreviations used: RNAP, RNA polymerase; DMS dimethyl sulfate; $(\mathrm{OP})_{2} \mathrm{Cu}, 1,10$-phenanthroline-copper.

E-mail address of the corresponding author: vraj@cge.iisc.ernet.in contributes to the mechanism of transcription activation (Raibaud \& Schwartz, 1984; Ishihama, 1993; Niu et al., 1996).

Here, we have investigated the role of bacteriophage $\mathrm{Mu} \mathrm{C}$ protein in the transcription activation of the mom gene promoter. The mom gene product encodes a novel DNA-modification function of the phage (Kahmann \& Hattman, 1987). Expression of the mom gene is controlled in a complex manner at both the transcriptional and translational levels (Hattman, 1982; Bolker \& Kahmann, 1989; Hattman et al., 1991; Wulczyn \& Kahmann, 1991). Positive control of mom gene expression is brought about by the C protein (Hattman et al., 1985; Heisig \& Kahmann, 1986), which is a site-specific DNA binding protein that functions as an activator of transcription from the four late promoters, $\mathrm{P}_{\text {lys, }}$ $\mathrm{P}_{p}, \mathrm{P}_{i}$ and $\mathrm{P}_{\text {mom }}$, of phage $\mathrm{Mu}$ (Bolker et al., 1989; Chiang \& Howe, 1993). The C binding site has been located from the -28 to the -57 position (Gindlesperger \& Hattman, 1994; De et al., 1998; Ramesh, 1997) in $\mathrm{P}_{\text {mom }}$ (Figure 1). C protein binds to its site as a dimer (De et al., 1997) with a very high affinity (Ramesh et al., 1994a), and $\mathrm{Mg}^{2+}$ acts as a cofactor for this site-specific binding (De et al., 1998). In the absence of C protein, E. coli RNAP binds to an upstream apparently non-functional 


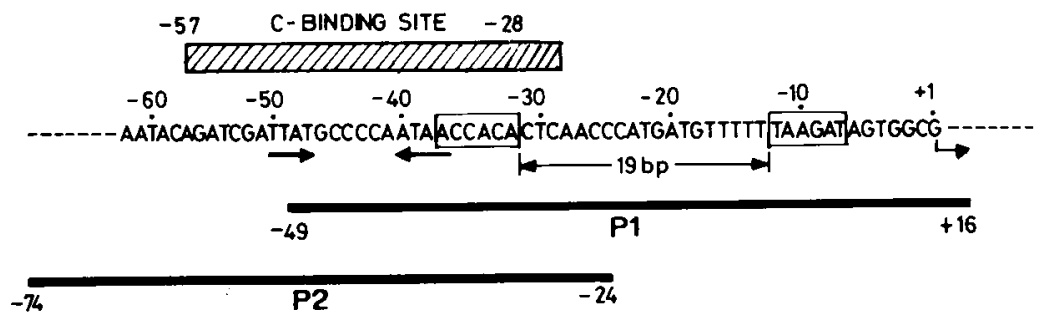

Figure 1. The Mu mom regulatory region. The $\mathrm{C}$ binding site located between -57 and -28 is shown as a hatched box. The tetranucleotide palindromic sequence within the $\mathrm{C}$ binding site is shown with two inverted arrows. The -10 and -35 promoter elements are boxed. The regions protected by RNAP in the presence (P1) and absence (P2) of C protein are indicated with thick lines. The $19 \mathrm{bp}$ spacer region and the +1 start site of P1 are indicated. promoter $\mathrm{P} 2$. In the presence of $\mathrm{C}$, it binds to the downstream functional promoter P1 (Balke et al., 1992), which shows the characteristics of an activator-dependent weak promoter (Raibaud \& Schwartz, 1984; Nagaraja, 1993). P1 has a poor -35 region (ACCACA) and a suboptimal $19 \mathrm{bp}$ spacer region between the -10 and -35 sequences (Figure 1).

The contact points for $\mathrm{C}$ protein at its specific binding site in $\mathrm{P}_{\text {mom }}$ have been determined using various footprinting agents (Ramesh \& Nagaraja, 1996; Sun et al., 1997). These studies indicate that C protein binds to one face of the helix, distorts DNA and makes major groove contacts. Now, we have carried out an in-depth analysis of C-mediated conformational changes in the mom promoter region. The $\mathrm{C}$ protein-mediated distortion is asymmetric in nature, and the binding leads to localized unwinding of DNA, which could be a prerequisite for the transactivation of $\mathrm{P}_{\text {mom }}$.

\section{Results}

\section{In vivo dimethyl sulfate footprinting analysis with $\mathrm{C}$ protein}

Site-specific interaction of $\mathrm{C}$ protein at its target site in the mom promoter region was studied by in vivo footprinting analysis. This type of analysis would show contact points and distortions brought about by the protein upon binding to its cognate site. Such an analysis with supercoiled plasmid would serve two purposes. It provides a realistic assessment of (1), protein contact in the natural context and (2) the influence of overall topological constraints (if any) on protein binding. Dimethyl sulfate (DMS) serves as a useful probe for examining protein-DNA interactions in vivo by the primer-extension analysis (Borowiec \& Gralla, 1986).

The cells harboring the plasmid containing the mom regulatory region ( $\mathrm{pBM} 2)$ were treated with DMS under conditions of $C$ protein expression as described in Materials and Methods. The DNA was cleaved with piperidine to display the contacts with the N7 group of guanine residues in the top and bottom strands (Figure 2(a) and (b)). The pattern of DNA methylation of naked DNA by DMS under identical conditions served as the control.
The -35 and -36 Gs in the bottom strand were protected completely against methylation, whereas the $-52 \mathrm{G}$ in the top strand was protected to a lesser extent. Thus, the protected region extends beyond the interrupted palindromic sequence (Figure 1). The Gs at positions $-33,-43$ and -53 in the bottom strand and the adenine at the -37 position in the top strand were hyper-methylated. This enhanced activity could be a result of a more exposed site caused by protein-induced structural alterations. The ten base-pair periodicity of hypersites $(-33 G,-43 G$ and $-53 G)$ in the bottom strand could reflect the protein-induced bending. Densitometric scanning (Figure 3) of protected and hypersensitive Gs indicate different intensities of reactivity. While the -35 and $-36 \mathrm{Gs}$ show complete protection (unlike the $-52 \mathrm{G}$ ), the $-53 \mathrm{G}$ located adjacent to the $5^{\prime}$ half site exhibits maximum hyper-reactivity amongst the three hyperreactive Gs. Thus, the overall interaction pattern seems to be asymmetric despite having an internal palindromic sequence in the $C$ binding site. This point is further supported by an in vitro $A>G$ DMS reaction wherein the -37 adenine in the top strand is hypersensitive upon $C$ protein binding (Figure 2(c)). This " $\mathrm{A}$ " is localized at the $3^{\prime}$ half site and is the only hypersensitive adenine amongst the eight " $\mathrm{A}$ " $\mathrm{S}$ of the internal palindromic sequence (5'-TTAT-ATA $\left.-5^{\prime}\right)$ found in the $C$ recognition site. In this $A>\bar{G}$ analysis, the -33 and -43 Gs (bottom strand) also showed hyper-reactivity to some extent. The overall protein contacts mapped by in vivo experiments are in agreement with those obtained by in vitro DMS-protection analysis with double-stranded DNA fragments containing the C binding site (Ramesh \& Nagaraja, 1996; Sun et al., 1997). Based on the G-protection analysis described here and earlier, the minimal target site of $\mathrm{C}$ at $\mathrm{P}_{\text {mom }}$ is $5^{\prime}$-GATTATgcccaATAACC-3'.

\section{$(\mathrm{OP})_{2} \mathrm{Cu}$ footprinting analysis of the mom regulatory region}

In vivo footprinting and the in vitro $\mathrm{A}>\mathrm{G}$ DMS reaction indicated asymmetric distortion of the $C$ binding site upon protein binding. Complete protection of the -35 and -36 Gs (as opposed to the 
(a)

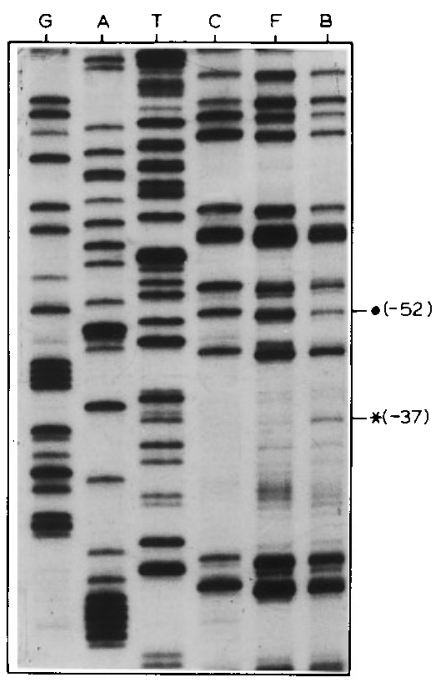

5'- CAGATCGATTATG CCCCAATAÁCCACACT-3', 3 - GTCTAGGTAATACGGGGTTATTGGTGTGA -5

(c) $\frac{F_{B}}{F F_{B}}$
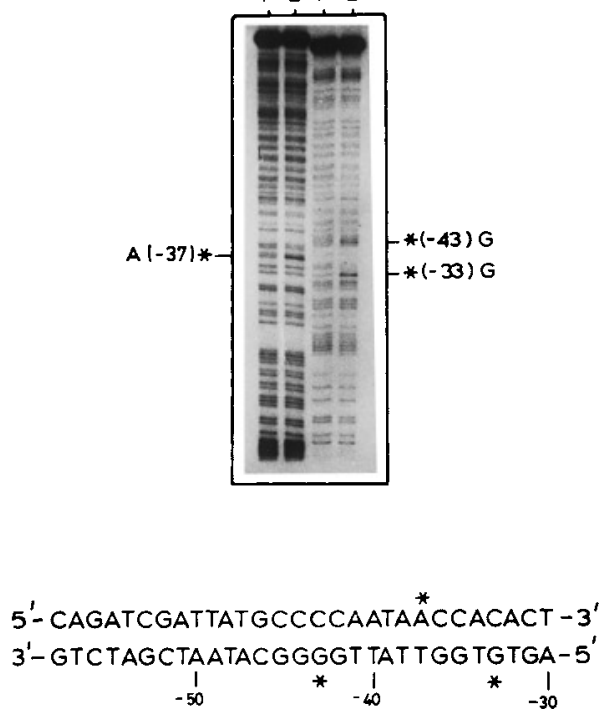

$-52 \mathrm{G})$ and the hypersensitivity of the $-37 \mathrm{~A}$ reflects the asymmetric interaction of $C$ with the target site (Figures 2 and 3; see also Figure 5). This could also be inferred from the pattern obtained with hydroxy-radical footprinting (Ramesh \& Nagaraja, 1996; Sun et al., 1997). The region towards the end of the $3^{\prime}$ half site in the top strand was more accessible to free radicals compared to the other two protected regions, while the bottom strand showed three protected regions of near equal intensity. The chemical nuclease 1,10-phenanthroline-copper $\left((\mathrm{OP})_{2} \mathrm{Cu}\right)$, which has the ability to detect protein-induced conformational changes in DNA (Spassky \& Sigman, 1985), was used to address this aspect further. This minorgroove-specific ligand is also known to intercalate into underwound DNA (Sigman et al., 1991). (b)

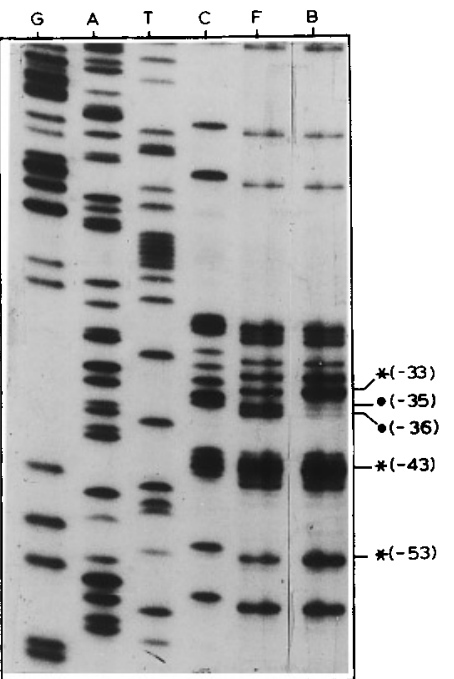

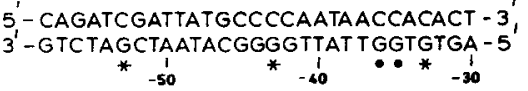

Figure 2. DMS footprinting analysis of the mom promoter region. The in vivo DMS methylation protection pattern $(\mathrm{G}>\mathrm{A})$ of the top strand (a) and the bottom strand (b). G, A, T and C refer to Sanger's dideoxy sequencing ladder. $\mathrm{F}$ and $\mathrm{B}$ indicate the methylation pattern in the absence and presence of $C$ protein, respectively. Protected bases are shown with a filled circle and the hypersites are indicated with asterisks. The numbers indicate the positions of the modified bases in the sequence. (c) In vitro DMS footprinting analysis (enhanced adenine cleavage) of $\mathrm{C}$ protein. TOP and BOTTOM refer to the top strand and the bottom strand of the mom promoter region. The -37 A hypersite is indicated with an asterisk.

A supercoiled plasmid containing the mom promoter region was used for the footprinting analysis, as it allows a more realistic assessment of interactions as compared to a linear fragment. Figure 4 shows the protection pattern on the top strand of the mom promoter region. While C-mediated protection was observed, there are two hypersensitive residues at positions -31 and -32 ( $C$ and $A)$, which lie in the region flanking the $3^{\prime}$ half site of the C-binding site. The bottom strand footprint does not show any such hypersensitive sites upon protein binding (results not shown). A summary of the footprinting data is shown in Figure 5 . $(\mathrm{OP})_{2} \mathrm{Cu}$ footprinting carried out with a linear fragment also showed hypersensitivity in the three bases (CAC) at positions $-31,-32$ and -33 of the top strand (Ramesh \& Nagaraja, 1996). The minor difference 
(a)
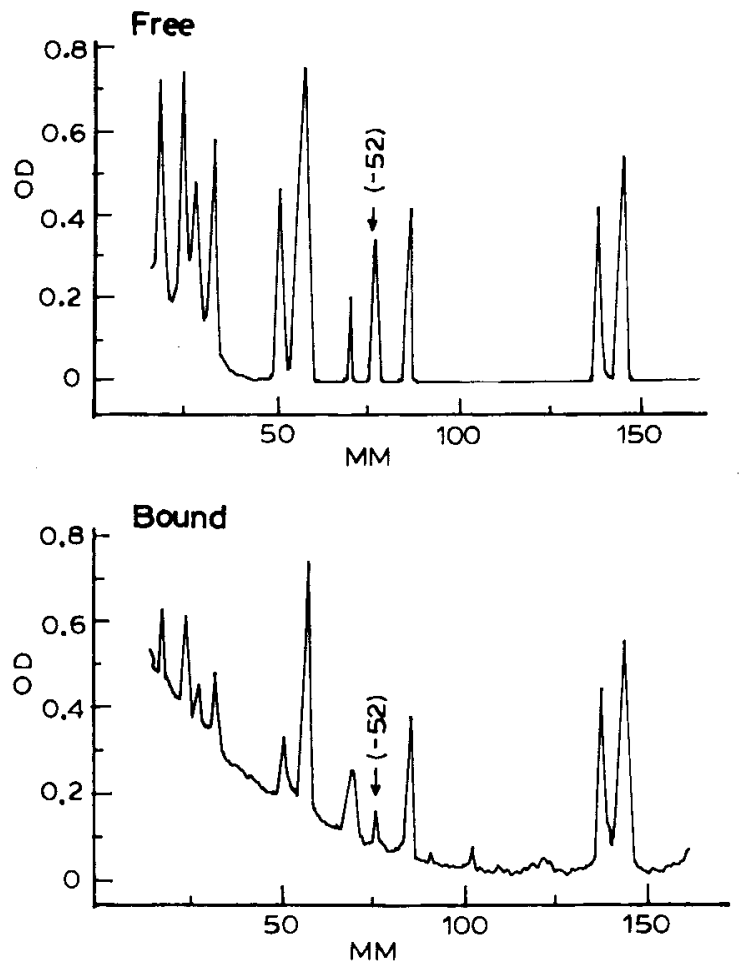
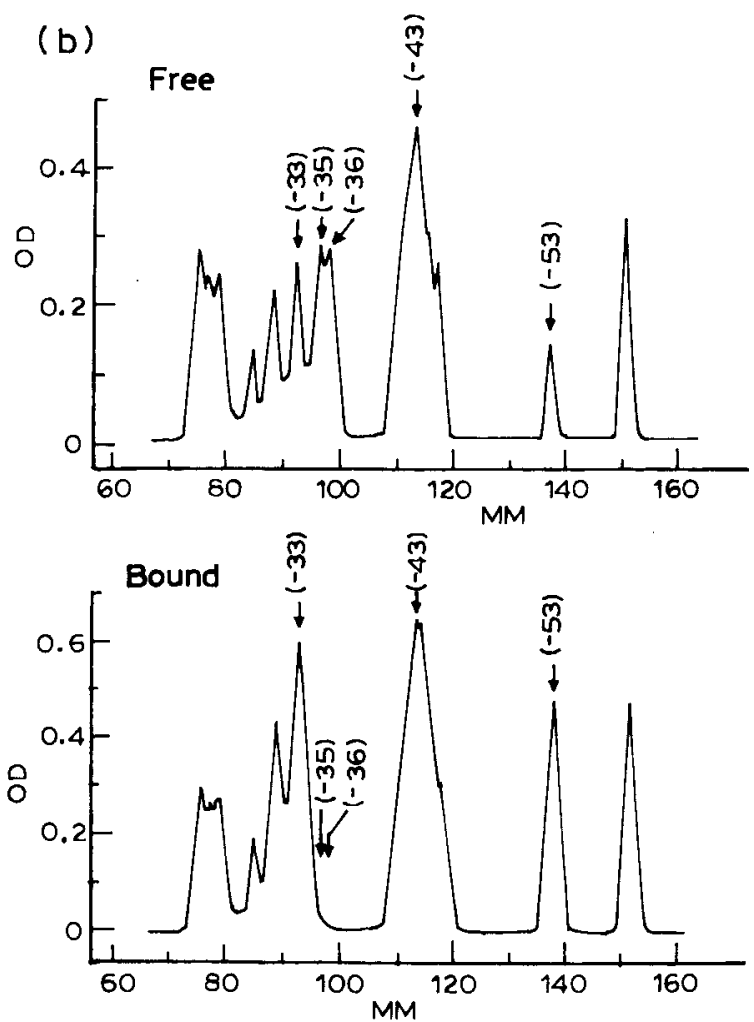

Figure 3. Densitometric scan of Figure 2(a) and (b): (a) top and (b) bottom strand of the mom promoter region. The protected and the hypersensitive bases are indicated.

in the hypersensitivity pattern in these different sets of experiments could be due to the choice of templates having different topological forms. The
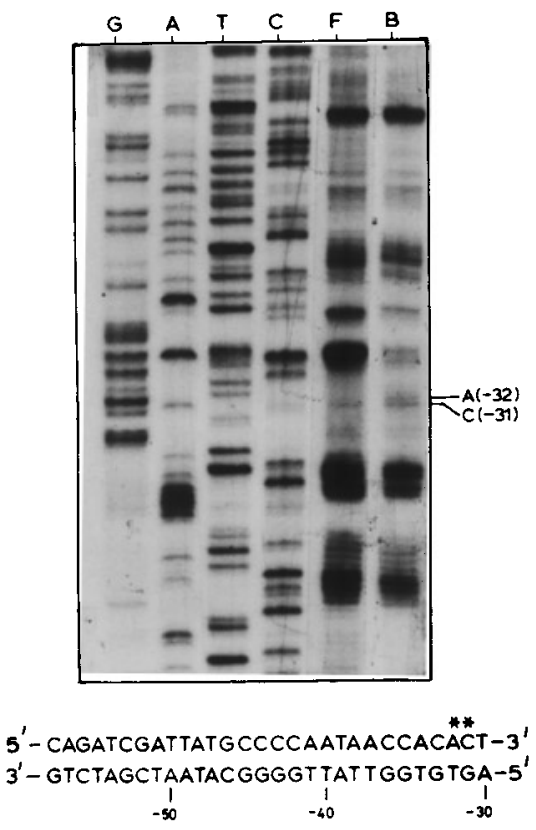

Figure 4. $(\mathrm{OP})_{2} \mathrm{Cu}$ footprinting of the mom promoter region. The cleavage pattern of the top strand was analysed in the absence $(\mathrm{F})$ and presence $(\mathrm{B})$ of $\mathrm{C}$ protein. $G, A, T$ and $C$ refer to Sanger's dideoxy sequencing ladder of the region. Hyper-reactive residues are indicated. enhanced cleavage observed above could reflect widening of the minor groove as a result of $\mathrm{C}$ binding. Widening of the minor groove could also be a consequence of the untwisting of DNA. Alternatively, a change in groove width could also be interpreted as the result of the protein-induced bending of DNA.

\section{C protein-induced untwisting of DNA}

A coupled topoisomerase assay was used to test whether C protein mediates the untwisting of the DNA. The topoisomer distribution would change when the DNA relaxation is carried out in the presence of a ligand which untwists or overtwists DNA. After removal of the ligand, the distribution of the topoisomer species would still conform to a Gaussian curve, yet differing from the preceding one by its median, and in some cases by its width. The change in the position of the median between

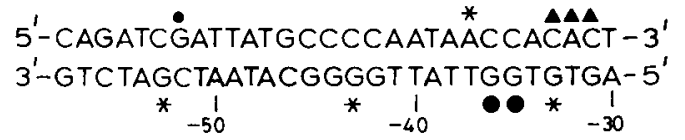

- Protected residues 7 DMS FOOTPRINTING ANALYSIS

- Hypersensitive residues - (OP) ${ }_{2}$ CU FOOTPRINTING ANALYSIS

Figure 5. Summary of the footprinting data. 
(a)

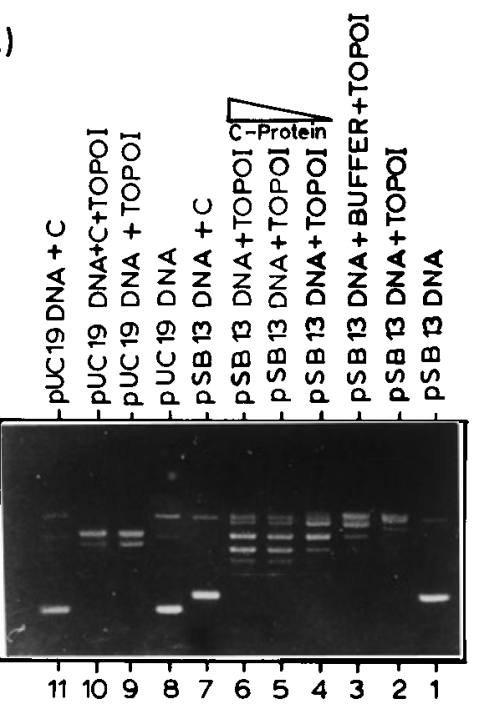

(b)
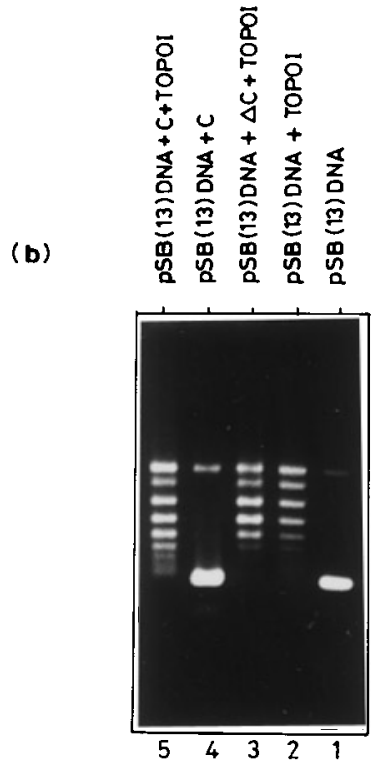

(c)

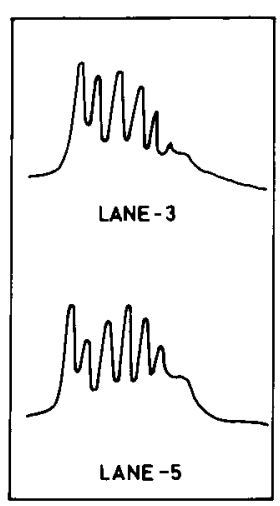

Figure 6. Coupled topoisomerase assay. (a) Supercoiled pSB13 (0.3 pmol, lane 1) was relaxed with 0.5 unit of E. coli topoisomerase I (lane 2) in the presence of C protein storage buffer (lane 3) and 2.0, 4.0 and 6.5 pmol of purified C protein (lanes 4,5 and 6) at $37^{\circ} \mathrm{C}$. Topoisomerase I was omitted in lane 7. Supercoiled pUC19 DNA (0.3 pmol, lane 8) was similarly relaxed with topoisomerase I alone (lane 9) or in the presence of $6.5 \mathrm{pmol}$ of C protein (lane 10). C protein incubated with pUC19 is shown in lane 11. (b) Supercoiled pSB13 DNA (0.6 pmol, lane 1) was relaxed with 0.5 unit of E. coli topoisomerase I (lane 2) in the presence of 8.4 pmol of heat-denatured C protein (lane 3) or native C protein (lane 5). Topoisomerase I was omitted in lane 4. (c) Densitometric scan of lanes 3 and 5 from (b).

the two experiments characterizes the change in the linking number at the time of ring closure and therefore the topological winding of the DNA induced by the ligand (Kolb \& Buc, 1982). The results of such an experiment with $C$ protein and negatively supercoiled pSB13 DNA (see Materials and Methods) are presented in Figure 6(a). Preincubation with increasing amounts of $\mathrm{C}$ protein (lanes 4, 5 and 6) results in shifting the topoisomer distribution to a greater mobility relative to the control samples (lanes 2 and 3). Further, such an increase in $C$ concentration did not alter the topoisomer pattern. Under these saturating amounts of C, pUC19 DNA does not show any change in the topoisomer distribution (compare lanes 6 and 10, Figure 6(a)). Heat-inactivated $C$ protein does not form a specific complex with DNA, and hence the topoisomer distribution remains unaltered (Figure 6(b), lanes 2 and 3). The C proteinmediated change in the linking number of pSB13 could be due to either the overtwisting or untwisting of DNA. In order to distinguish between these two possibilities, the reaction products in lane 6 , Figure 6(a) were further incubated with E. coli topoisomerase I, which can relax only negatively supercoiled DNA. The complete relaxation of topoisomers in this experiment confirmed that $\mathrm{C}$ protein induces the untwisting and not the overtwisting of DNA. The experiment depicted in Figure 6(b) was carried out to obtain a Gaussian distribution of the topoisomers in order to determine the C protein-mediated untwisting angle. Since writhe is likely to make a negligible contribution to the linking number of a fully relaxed topoisomer, the $\delta L \mathrm{k}$ values predominantly reflect changes in twist. The densitometric scan of the control lane (lane 3) and the test lane (lane 5) of Figure 6(b) are shown in Figure 6(c). The change in the average linking number was determined using the method of Kolb \& Buc (1982). The $\delta L \mathrm{k}$ value for the $C$ protein was calculated to be 1.04 turns of DNA or $28.8^{\circ}$ untwisting per C binding site.

\section{Localized unwinding of DNA by $\mathrm{C}$ protein}

$(\mathrm{OP})_{2} \mathrm{Cu}$ footprinting with the mom promoter region showed hypersensitivity at $\mathrm{AC}$ bases located at the $3^{\prime}$ half site of the $C$ recognition sequence, reflecting the $C$ protein-induced untwisting of the DNA. Though the protein binds to DNA as a dimer (De et al., 1997) and interacts with a sequence having an internal palindrome, it seems to untwist the DNA only at the $3^{\prime}$ half site (at CAC; Ramesh \& Nagaraja, 1996). In order to determine whether this increased reactivity is the property of the sequence per se, we carried out $(\mathrm{OP})_{2} \mathrm{Cu}$ footprinting with the supercoiled plasmid pSB3 (containing a trimeric repeat of the $C$ binding site), but having a different sequence in the hypersite region (CGA instead of CAC in the positions corresponding to $-31,-32$ and -33). The results of such an analysis showed an increased reactivity only towards the $3^{\prime}$ end of the third $C$ binding site. No major hypersites were seen at the $5^{\prime}$ end of the first $C$ binding site. The hypersites at the $3^{\prime}$ end in this case were offset by $2 \mathrm{bp}$ (Figure 7) as compared to the hypersite position at $\mathrm{P}_{\text {mom }}$. This shift in the position of the hypersites in the case of pSB3 could be because of the 


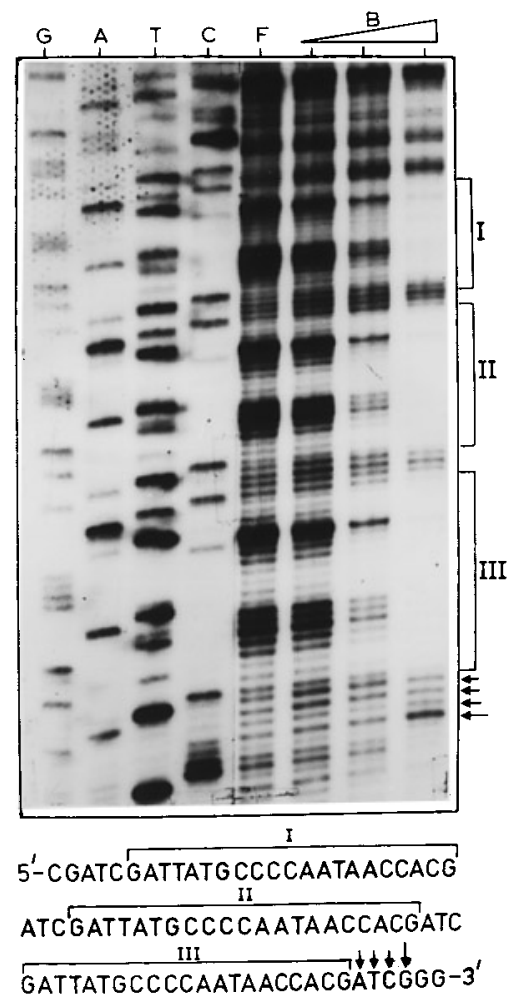

Figure 7. $(\mathrm{OP})_{2} \mathrm{Cu}$ footprinting with the multiple $\mathrm{C}$ binding sites. $\mathrm{G}, \mathrm{A}, \mathrm{T}$ and $\mathrm{C}$ indicate Sanger's dideoxy sequencing ladder. $\mathrm{F}$ indicates the cleavage pattern in the absence of $\mathrm{C}$ protein and $\mathrm{B}$ indicates the pattern in the presence of increasing amounts $(200,250$ and $300 \mathrm{ng}$ ) of $\mathrm{C}$ protein. Arrows indicate the hypersensitive bases on the gel and in the nucleotide sequence. I, II and III represent $\mathrm{C}$ sites protected upon $\mathrm{C}$ binding. The sequencing lane is of the complementary strand of the sequence shown below the gel.

binding of $\mathrm{C}$ protein to three closely placed sites oriented in the same direction. This point can also account for the absence of any major hyper-reactive bands between the three $\mathrm{C}$ binding sites. Hypersensitivity in the same position (corresponding to -31, -32 and -33 ), but with a different sequence (CGG or CGA instead of CAC) was observed when a single $\mathrm{C}$ binding site was used for $(\mathrm{OP})_{2} \mathrm{Cu}$ analysis (results not shown). The following conclusions could be drawn from these experiments: (1) untwisting is localized only in the $3^{\prime}$ half site of the $C$ recognition sequence; and (2) the untwisting activity of $\mathrm{C}$ protein is independent of the flanking sequences.

\section{Discussion}

Here, we have addressed the role of the sequence-specific binding of bacteriophage $\mathrm{Mu} \mathrm{C}$ protein in mom gene transactivation. We demonstrate site-specific, yet asymmetric, interaction of bacteriophage $\mathrm{Mu} \mathrm{C}$ protein at its recognition sequence. While this small protein makes an extended contact, it distorts the DNA. The binding of $C$ leads to a localized untwisting of the DNA towards the distal region downstream of the $3^{\prime}$ half site.

The C protein binding site is located upstream of and overlapping the -35 element of the mom promoter. Thus, $\mathrm{C}$ binding may result in the bending of the DNA, which could help in protein-protein interaction to influence transcription. DMS-footprinting experiments suggest such axial flexibility of the DNA. These data represent a realistic picture as the experiments were carried out with supercoiled plasmid under in vivo conditions. The data are in agreement with our in vitro footprinting data (Ramesh \& Nagaraja, 1996) and those of Sun et al. (1997). Bending was also observed when a circular permutation assay was carried out with a $50 \mathrm{bp}$ fragment from the mom promoter region having the C recognition sequence by Sun et al. (1997). A single TGTG motif is found in their sequence and in the footprinting substrates used here. It should be noted that the TGTG motif is kink prone and could be contributing to the protein-induced bending of DNA. The CAP protein recognition sequence has this motif on either side of its binding site, resulting in a symmetric bending/distortion of the DNA (Kolb et al., 1993). The presence of TGTG at only one side of the $C$ recognition site could be contributing to the axial flexibility and asymmetric distortion induced by $C$ protein binding. The dimeric C protein (De et al., 1997) seems to bind to its site in a symmetric fashion, based on the DNase I protection pattern (Gindlesperger \& Hattman, 1994; Ramesh, 1997).

$\mathrm{C}$ protein joins the growing family of DNA-binding proteins that exert their effect by unwinding DNA. MerR, DnaA protein, histone H1, and DNA ligase (Ansari et al., 1995; Mizushima et al., 1996; Ivanchenko et al., 1996a,b) are the well-characterized examples. Amongst these proteins, MerR serves as a classic example of a transcription factor which mediates the unwinding of its target site to bring about transcription activation of the merT promoter. MerR protein binds at the $19 \mathrm{bp}$ spacer region of the merT promoter and allosterically regulates the expression of $\mathrm{a} \mathrm{Hg}^{2+}$-resistance operon in response to mercury by controlling the DNA conformation (Frantz \& O'Halloran, 1990). The activation of its target gene takes place by compensating for the overtwisting between the -35 and -10 elements (Ansari et al., 1992, 1995). The protein-DNA interactions in MerR and C protein are, however, distinct, though the mechanisms of their action seem to be the same. The interaction is different because their target sequences and their locations with respect to the promoters are different. The MerR binding site consists of a $7 \mathrm{bp}$ inverted repeat interrupted by $4 \mathrm{bp}$ (Summers, 1992), whereas the $C$ protein binding site in $P_{\text {mom }}$ (5'-GATTATgcccaATAACC-3') has an internal tetranucleotide palindromic sequence separated by a $6 \mathrm{bp}$ spacer. The binding site of MerR is located between the -10 and -35 boxes of the merT promoter. It has been proposed that mercury-depen- 
dent activation of the merT promoter brings the -10 and -35 elements into better helical alignment through a MerR-mediated DNA untwisting effect at the center of its binding site, resulting in a symmetric DNA distortion. This is in contrast to the asymmetric unwinding mediated by $\mathrm{C}$ protein. The asymmetric interaction of the $C$ protein could be necessary because of its binding upstream of and overlapping the -35 element, unlike that of MerR. The protein-DNA interactions in these two similar yet different systems could also be influenced by the respective protein structures. A parallel could be drawn for their response to metal ions. $\mathrm{C}$ protein binds to its target site only in the presence of $\mathrm{Mg}^{2+}$ (Ramesh et al., 1994a). The presence of $\mathrm{Mg}^{2+}$ results in conformational changes leading to more $\alpha$-helicity and DNA binding (De et al., 1998). MerR is also subjected to $\mathrm{Hg}^{2+}$-mediated conformational changes (Frantz \& O'Halloran, 1990).

We envision the following scenario for C-mediated transcription activation of the mom promoter (Figure 8 ). In the absence of $C$ protein, RNAP is unable to bind to $\mathrm{P}_{\text {mom }}$, probably due to unfavorable interactions with the -35 and -10 elements of the promoter. The mom promoter (Figure 1) has a $19 \mathrm{bp}$ spacer separating the -10 and -35 regions, as compared to the optimal 17 $( \pm 1)$ bp spacing seen in a large number of the promoters. The $19 \mathrm{bp}$ spacer adds an additional twist angle of at least $34^{\circ}$, and the two elements may be out of phase with respect to each other. The $C$ protein-induced torsional change in DNA unwinding (by $\sim 30^{\circ}$ ) could compensate adequately for this difference. Thus, upon binding to its cognate site, $C$ could untwist the DNA so as to reorient the pro-

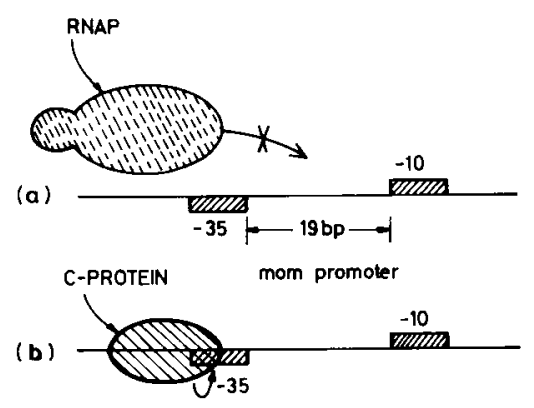

UNTWISTING BY C-PROTEIN

(c)

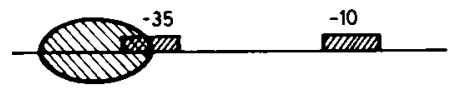

(d)

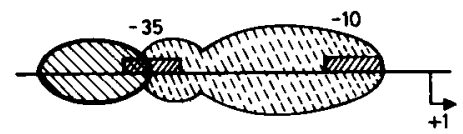

Figure 8. A model for $C$ protein-mediated mom gene transactivation. (a) In the absence of $C$ protein, RNAP is unable to bind to $\mathrm{P}_{m o m}$. (b) $\mathrm{C}$ protein binds to its cognate site in $\mathrm{P}_{\text {mom }}$ and unwinds the DNA. (c) Reorientation of the two promoter elements. (d) RNAP is now able to make favorable contacts with $\mathrm{P}_{\text {mom }}$. moter elements. Reorientation of the promoter elements would enable RNAP to recognize the mom promoter. It remains to be demonstrated whether RNAP recognizes only the -10 or both the promoter elements in the presence of $C$ protein. It is possible that alternate and/or additional explanations could account for C-mediated mom transactivation. C-induced bending (Sun et al., 1997) or overall distortion (Ramesh \& Nagaraja, 1996; Sun et al., 1997; present study) of DNA could play an important role in promoter occupancy by RNAP. In addition, protein-protein interactions between $C$ and RNAP could also contribute in the initiation of mom transcription. The majority of the transcription activators studied so far interact with one or other of the subunits of RNAP (Ishihama, 1992, 1993; Niu et al., 1996). A recent report shows that $C$ protein does not interact with the $\alpha$ or $\sigma$ subunits of RNAP (Sun et al., 1998). While the interaction of $C$ with the $\beta$ or $\beta^{\prime}$ subunits of RNAP is yet to be assessed, DNA distortion and/or untwisting seems to be a major mechanism operating for mom activation.

The complexity of mom gene regulation is beginning to be understood. Dam methylation of adenine residues in three closely spaced GATCs located immediately upstream of the $C$ recognition site is required for mom gene expression (Seiler et al., 1986). Dam methylation blocks the binding of another host protein, OxyR, which represses mom transcription in $\mathrm{dam}^{-}$strains (Bolker \& Kahmann, 1989). The situation becomes more complex with the observation that the reduced form of OxyR does not inhibit $C$ protein binding to its site (Sun \& Hattman, 1996). However, prior binding of the reduced form of OxyR prevents RNAP binding at P2 as well as C-activated RNAP binding at P1. In circumstances where OxyR is not bound to its site, RNAP would bind to P2 (Balke et al., 1992). C protein binding to its site would then displace RNAP from P2. It is still unclear to us as to how, with the interplay of these factors, RNAP is recruited to $\mathrm{P} 1$ to bring about mom gene expression inside the cell.

\section{Materials and Methods}

\section{Strains, plasmids, enzymes and chemicals}

E. coli DH10B was used for generating different plasmid constructs. E. coli BL26(DE3), having a C overexpressing plasmid, was employed for both in vivo DMS footprinting and for $\mathrm{C}$ protein purification. Table 1 shows the list of plasmids used here. The various restriction enzymes and modifying enzymes were purchased from Pharmacia, New England Biolabs, Amersham and Boehringer Mannheim, and were used according to the suppliers', recommendations. Chemicals and other reagents were purchased from Sigma, Gibco BRL and High Media. Primers and DNA oligonucleotides were synthesized by Bangalore Genei (Pvt.) Ltd, Bangalore, India. $\left[\alpha-{ }^{32} \mathrm{P}\right] \mathrm{dATP}$ and $\left[\gamma_{-}{ }^{32} \mathrm{P}\right] \mathrm{ATP}$ were purchased from Amersham Corp. C protein was purified from E. coli 
Table 1. Plasmids used

\begin{tabular}{|c|c|c|}
\hline Plasmids & Description & Reference \\
\hline pCSM1 & $\begin{array}{l}\text { Single C binding site (5'-AGATCGATTATGCCCCAATAACCAC-3') cloned into the SmaI } \\
\text { site of pUC19 }\end{array}$ & $\begin{array}{l}\text { B. D. Paul and V. N., } \\
\text { unpublished results }\end{array}$ \\
\hline pSB13 & $13 \mathrm{C}$ binding sites in the same orientation cloned into the SmaI site of pUC19 & This study \\
\hline pSB3 & Three C-binding sites in the same orientation cloned into the SmaI site of pUC19 & This study \\
\hline pUW4 & $\begin{array}{l}\text { mom promoter region ( } 260 \mathrm{bp} \text { EcoRI-HindIII fragment from pLW4; Balke et al., 1992) } \\
\text { cloned into the EcoRI-BamHI site of pUC19 }\end{array}$ & Ramesh et al. (1994a) \\
\hline pBM2 & $\begin{array}{l}220 \mathrm{bp} E c o \mathrm{RI} / \mathrm{BamHI} \text { fragment from pUW4 containing the mom promoter region cloned } \\
\text { into the BanII site of the pLysS vector }\end{array}$ & $\begin{array}{l}\text { B. D. Paul and V. N., } \\
\text { unpublished results }\end{array}$ \\
\hline pVR7 & C-gene overexpressing plasmid & Ramesh et al. (1994a) \\
\hline pUC19 & Laboratory stock & Sambrook et al. (1989) \\
\hline
\end{tabular}

BL26(DE3) carrying plasmid pVR7 as described by Ramesh et al. (1994a,b). Most of the standard procedures were carried out as described by Sambrook et al. (1989).

\section{Construction of pSB13 and pSB3 plasmids}

Two oligonucleotides (5'-CGATCGATTATGCCCCAATAACCA- $3^{\prime}$ and 5'-GATCGTGGTTATTGGGGCATAATC $-3^{\prime}$ ) containing the $C$ binding site were designed in such a way that annealing and subsequent ligation would result in multimerization of the $C$ binding sites only in one orientation. Samples (150 pmoles) of the above oligonucleotides were annealed in a buffer containing $20 \mathrm{mM}$ Tris- $\mathrm{HCl}$ ( $\mathrm{pH} 7.2), 1 \mathrm{mM}$ EDTA, $5 \mathrm{mM}$ $\mathrm{MgCl}_{2}$, and $50 \mathrm{mM} \mathrm{NaCl}$, phosphorylated using T4 polynucleotide kinase, and then subjected to self ligation using T4 DNA ligase. This mixture of the multimerized $\mathrm{C}$ binding sites were blunted and then cloned into the SmaI site of the pUC19 vector. Clones having different numbers of the single $\mathrm{C}$ binding sites were obtained. Of these, two clones were used here: pSB13 contains $13 \mathrm{C}$ binding sites and pSB3 has three $C$ binding sites, all in the same orientation. Dideoxy sequencing was employed to confirm the sequences (Sambrook et al., 1989).

\section{In vivo DMS protection analysis}

E. coli BL26(DE3) cells harboring pVR7 (a C gene overexpressing plasmid) and pBM2 (a plasmid containing the mom promoter region) were grown to $A_{600} 0.6$ in $20 \mathrm{ml}$ of Luria-Bertani medium. Cultures were induced with $0.3 \mathrm{mM}$ IPTG for the expression of $\mathrm{C}$ protein, and were further grown for one hour. Cells were treated with $6 \mathrm{mM}$ dimethyl sulfate (DMS) for five minutes. The reaction with DMS was stopped by transferring the cultures to pre-chilled tubes. The cells were harvested and the plasmids isolated by the alkaline-lysis method (Sambrook et al., 1989). The DMS-modified plasmid DNA was subjected to cleavage by the addition of $10 \mu \mathrm{l}$ of piperidine to $90 \mu \mathrm{l}$ of methylated DNA and heating to $90^{\circ} \mathrm{C}$ for 30 minutes followed by freeze drying. The DNA was resuspended in $100 \mu$ of sterile distilled water and again freeze dried. A final round of freeze drying was performed after resuspending the DNA in $20 \mu \mathrm{l}$ of distilled water. The DNA was purified by passing it through Sephadex G-50 columns. The mom forward primer (5'-GAAACGAGCGCATATA-3') and mom reverse primer (5'-TGTTATTTAAGGCGGATTCC-3') which anneal upstream of the -96 position and downstream of the +56 position, respectively (with respect to the +1 (transcription start site) position of the mom gene), were end-labeled with $\left[\gamma^{32} \mathrm{P}\right] \mathrm{ATP}$ and $\mathrm{T} 4$ polynucleotide kinase and purified by passing through Sephadex G-25 columns. End-labeled primer $\left(2 \times 10^{6} \mathrm{cpm}\right), 1-2 \mu \mathrm{g}$ of piperidine-cleaved plasmid DNA and $1.0 \mathrm{mM} \mathrm{NaOH}$ were mixed to a total volume of $40 \mu \mathrm{l}$, heated to $80^{\circ} \mathrm{C}$ for two minutes and then immediately chilled followed by the addition of $5 \mu \mathrm{l}$ of primer-extension buffer $(0.5 \mathrm{mM}$ Tris- $\mathrm{HCl}$ (pH 7.2), $100 \mathrm{mM} \mathrm{MgSO}_{4}, 2.0 \mathrm{mM}$ DTT). After $40^{\circ} \mathrm{C}$ incubation for three minutes, $1 \mathrm{mM}$ dNTP mix was added and the extension reaction was carried out with one unit of Klenow enzyme at $45^{\circ} \mathrm{C}$ for ten minutes. Reactions were stopped by adding $17 \mu \mathrm{l}$ of Klenow stop mix (4.0 M ammonium acetate, $20 \mathrm{mM}$ EDTA). The DNA was precipitated by adding $2.5 \times$ volume of $100 \%$ $(\mathrm{v} / \mathrm{v})$ ethanol and then loaded onto a denaturing $6 \%$ $(\mathrm{w} / \mathrm{v})$ polyacrylamide gel. Dideoxy sequencing reactions with the same labeled primers were also carried out with the pBM2 plasmid template and loaded onto the gel. The gel was then exposed to Kodak X-ray film to obtain the autoradiogram. The autoradiograms were scanned on a BioRad (Hercules, CA) model GS-700 densitometer using the Molecular Analyst program.

\section{In vitro $A>G$ DMS reaction}

The cleavage at methylated purine nucleotides $(A>G)$ was performed as described by Maxam \& Gilbert (1977). The methylated DNA was suspended in $20 \mu \mathrm{l}$ of sterile distilled water, chilled on ice, $5 \mu \mathrm{l}$ of $0.5 \mathrm{M} \mathrm{HCl}$ was added and the sample was incubated for two hours on ice with occasional mixing. The DNA was precipitated, dissolved in $100 \mu \mathrm{l}$ of $0.1 \mathrm{M} \mathrm{NaOH}, 1 \mathrm{mM}$ EDTA, heated at $90^{\circ} \mathrm{C}$ for 30 minutes for strand cleavage, and recovered by precipitation.

\section{$(\mathrm{OP})_{2} \mathrm{Cu}$ footprinting}

C protein-DNA (7.8:1 pmol) complexes were formed in $180 \mu \mathrm{l}$ of binding buffer $(20 \mathrm{mM}$ Tris- $\mathrm{HCl}$ ( $\mathrm{pH} 7.2)$, $1 \mathrm{mM}$ EDTA, $5 \mathrm{mM} \mathrm{MgCl} 2,50 \mathrm{mM} \mathrm{NaCl}$ ) by incubating on ice for ten minutes. A $10 \mu \mathrm{l}$ sample of $4 \mathrm{mM}$ 1,10-phenanthroline $/ 0.3 \mathrm{mM} \mathrm{CuSO}_{4}$ and $10 \mu \mathrm{l}$ of $58 \mathrm{mM}$ 3-mercaptopropionic acid were added and incubated on ice for one minute. Digests were quenched by adding $7 \mu \mathrm{l}$ of $100 \mathrm{mM}$ 2,9-dimethyl-1,10-phenanthroline, deproteinised by phenol/chloroform extractions and the DNA was precipitated with ethanol. The DNA was purified by passing through Sephadex G-50 columns. pUC19 forward and reverse primers were end-labeled with $\left[\gamma^{32} \mathrm{P}\right] \mathrm{ATP}$ and used for primer extension of the DNA as described above. The extended products were electrophoresed on a denaturing $6 \%$ polyacrylamide gel. The gel was dried and exposed to X-ray film obtain the autoradiogram. 


\section{Coupled topoisomerase assay}

A supercoiled plasmid, pSB13 (with $13 \mathrm{C}$ binding sites) was constructed, as described above, for carrying out the coupled topoisomerase assay. This assay was performed as follows: $\mathrm{C}$ protein complexes were formed by incubating varying amounts of $\mathrm{C}$ protein with 0.6 pmol of supercoiled pSB13 plasmid or 0.4 pmol of pUC19 plasmid (for the control) in buffer containing $20 \mathrm{mM}$ Tris- $\mathrm{HCl}(\mathrm{pH} 7.2), 1 \mathrm{mM}$ EDTA, $5 \mathrm{mM} \mathrm{MgCl}_{2}$ and $50 \mathrm{mM} \mathrm{NaCl}$, on ice, for ten minutes. These complexes were incubated with $E$. coli topoisomerase I at $37^{\circ} \mathrm{C}$ for 15 minutes. The reactions were stopped by the addition of SDS to a final concentration of $1.5 \%(\mathrm{w} / \mathrm{v})$ and heat inactivation at $65^{\circ} \mathrm{C}$ for 20 minutes. The reaction mixes were electrophoresed on $1.2 \%(\mathrm{w} / \mathrm{v})$ agarose slab gel at $25^{\circ} \mathrm{C}$ in $1 \times \mathrm{TAE}$ buffer at $3 \mathrm{~V} / \mathrm{cm}$ for 16 hours. Gels were stained with ethidium bromide and photographed. The negatives were analyzed on a BioRad (Hercules, CA) model GS-700 densitometer using the Molecular Analyst program.

\section{Acknowledgments}

We thank Bindu Diana Paul for the plasmids and Tisha Bhaduri for providing the E. coli topoisomerase I. Thanks are due to S. Hattman and T. O'Halloran for their suggestions and critical reading of the manuscript. We also thank D. R. Radha and Jayashree for their technical help. S.B. is supported by the University Grants Commission, Government of India. The work was supported by a grant from the Department of Science and Technology, Government of India.

\section{References}

Ansari, A. Z., Chael, M. L. \& O'Halloran, T. V. (1992). Allosteric underwinding of DNA is a critical step in positive control of transcription by $\mathrm{Hg}-\mathrm{MerR}$. Nature, 355, 87-89.

Ansari, A. Z., Bradner, J. E. \& O'Halloran, T. V. (1995). DNA-bend modulation in a repressor-to-activator switching mechanism. Nature, 374, 371-375.

Balke, V., Nagaraja, V., Gindlesperger, T. \& Hattman, S. (1992). Functionally distinct RNA polymerase binding sites in the phage $\mathrm{Mu}$ mom promoter region. Nucl. Acids Res. 20, 2777-2784.

Bolker, M. \& Kahmann, R. (1989). The Escherichia coli regulatory protein OxyR discriminates between methylated and unmethylated states of the phage Mu mom promoter. EMBO J. 8, 2403-2410.

Bolker, M., Wulczyn, F. G. \& Kahmann, R. (1989). Role of bacteriophage $\mathrm{Mu} \mathrm{C}$ protein in activation of the mom gene promoter. J. Bacteriol. 171, 2019-2027.

Borowiec, J. A. \& Gralla, J. D. (1986). High resolution analysis of Lac transcription complexes inside cells. Biochemistry, 25, 5051-5057.

Busby, S. \& Ebright, R. (1994). Promoter structure, promoter recognition, and transcription activation in prokaryotes. Cell, 79, 743-746.

Chiang, L. W. \& Howe, M. M. (1993). Mutational analysis of a C-dependent late promoter of bacteriophage $\mathrm{Mu}$. Genetics, 135, 619-629.

Collado-Vides, J., Magasanik, B. \& Gralla, J. D. (1991). Control site location and transcriptional regulation in Escherichia coli. Microbiol. Rev. 55, 371-394.
De, A., Paul, B. D., Ramesh, V. \& Nagaraja, V. (1997). Use of protein A gene fusions for the analysis of structure-function relationship of the transactivator protein $\mathrm{C}$ of bacteriophage Mu. Protein Eng. 10, 935-941.

De, A., Ramesh, V., Mahadevan, S. \& Nagaraja, V. (1998). $\mathrm{Mg}^{2+}$ mediated sequence specific binding of transcriptional activator protein $C$ of bacteriophage $\mathrm{Mu}$ to DNA. Biochemistry, 37, 3831-3838.

Frantz, B. \& O'Halloran, T. V. (1990). DNA distortion accompanies transcriptional activation by the metal repressor gene-regulatory protein MerR. Biochemistry, 29, 4747-4751.

Gindlesperger, T. L. \& Hattman, S. (1994). In vitro transcriptional activation of the phage $\mathrm{Mu}$ mom promoter by C protein. J. Bacteriol. 176, 2885-2891.

Hattman, S. (1982). DNA methyltransferase dependent transcription of the phage Mu mom gene. Proc. Natl Acad. Sci. USA, 79, 5518-5521.

Hattman, S., Ives, J., Margolin, W. \& Howe, M. M. (1985). Regulation of the bacteriophage $\mathrm{Mu}$ mom gene: mapping of the transactivation (Dad) function to the C-region. Gene, 39, 71-76.

Hattman, S., Newman, L., Krishna, Murthy H. M. \& Nagaraja, V. (1991). Com, the phage Mu mom translational activator, is a zinc binding protein that binds specifically to its cognate mRNA. Proc. Natl Acad. Sci. USA, 88, 10027-10031.

Heisig, P. \& Kahmann, R. (1986). The sequence and mom transactivation function of the $\mathrm{C}$ gene of bacteriophage Mu. Gene, 43, 59-67.

Ishihama, A. (1992). Role of RNA polymerase $\alpha$ subunit in transcription activation. Mol. Microbiol. 6, 32833288 .

Ishihama, A. (1993). Protein-protein communication within the transcription apparatus. J. Bacteriol. 179, 2483-2489.

Ivanchenko, M., Hassan, A., van Holde, K. \& Zlatanova, J. (1996a). H1 binding unwinds DNA. Evidence from topological assays. J. Biol. Chem. 271, 3258032585.

Ivanchenko, M., van Holde, K. \& Zlatanova, J. (1996b). Procaryotic DNA ligases unwind superhelical DNA. Biochem. Biophys. Res. Commun. 226, 498-505.

Kahmann, R. \& Hattman, S. (1987). Regulation and expression of the mom gene. In Phage Mu (Symonds, N., Toussaint, A., Van de Putte, P. \& Howe, M. M., eds), pp. 93-109, Cold Spring Harbor Laboratory Press, Cold Spring Harbor, NY.

Kolb, A. \& Buc, H. (1982). Is DNA unwound by the cyclic AMP receptor protein?. Nucl. Acids Res. 10, 473-485.

Kolb, A., Busby, S., Buc, H., Garges, S. \& Adhya, S. (1993). Transcriptional regulation by cAMP and its receptor protein. Annu. Rev. Biochem. 62, 749-795.

Maxam, A. M. \& Gilbert, W. (1977). A new method for sequencing DNA. Proc. Natl Acad. Sci. USA, 74, 560-565.

Mizushima, T., Katayama, T. \& Sekimizu, K. (1996). Effect on DNA topology by DnaA protein, the initiation factor of chromosomal DNA replication in Escherichia coli. Biochemistry, 35, 11512-11516.

Nagaraja, V. (1993). Control of transcription initiation. J. Biosci. 18, 13-25.

Niu, W., Kim, Y., Tau, G., Heyduk, T. \& Ebright, R. (1996). Transcription activation at class II CAPdependent promoters: two interactions between CAP and RNA polymerase. Cell, 87, 1123-1134. 
Raibaud, O. \& Schwartz, M. (1984). Positive control of transcription initiation in bacteria. Annu. Rev. Genet. 18, 173-206.

Ramesh, V. (1997). DNA binding studies with the transcriptional activator protein $\mathrm{C}$ of bacteriophage $\mathrm{Mu}$. $\mathrm{PhD}$ thesis, Indian Institute of Science, Bangalore, India.

Ramesh, V. \& Nagaraja, V. (1996). DNA binding of the phage $\mathrm{Mu} \mathrm{C}$ protein: footprinting analysis reveals altered DNA conformation upon protein binding. J. Mol. Biol. 260, 22-33.

Ramesh, V., De A., \& Nagaraja, V. (1994a). Engineering hyperexpression of bacteriophage $\mathrm{Mu} \mathrm{C}$ protein by removal of secondary structure at the translational initiation region. Protein Eng. 7, 1053-1057.

Ramesh, V., De A., \& Nagaraja, V. (1994b). Overproduction and purification of C-protein, the late gene transcription activator from phage $\mathrm{Mu}$. Protein Expt. Purif. 5, 379-384.

Sambrook, J., Fritsch, E. F. \& Maniatis, T. (1989). Molecular Cloning: A Laboratory Manual, 2nd edit., Cold Spring Harbor Laboratory Press, Cold Spring Harbor, NY.

Seiler, A., Blocker, H., Frank, R. \& Kahmann, R. (1986). The mom gene of bacteriophage $\mathrm{Mu}$ : the mechanism of methylation dependent expression. EMBO J. 5, 2719-2728.

Sigman, D. S., Kuwabara, M. D., Chen, C.-H. B. \& Bruice, T. W. (1991). Nuclease activity of 1,10-phe- nanthroline-copper in study of protein-DNA interactions. Methods Enzymol. 208, 414-433.

Spassky, A. \& Sigman, D. (1985). Nuclease activity of 1,10-phenanthroline-ion. Conformational analysis and footprinting of the lac operon. Biochemistry, 24, 8050-8056.

Summers, A. O. (1992). Untwist and shout: a heavy metal-responsive transcriptional regulator. J. Bacteriol. 174, 3097-3101.

Sun, W. \& Hattman, S. (1996). Escherichia coli OxyR protein represses the unmethylated bacteriophage $\mathrm{Mu}$ mom operon without blocking binding of the transcriptional activator C. Nucl. Acids Res. 24, 40424049.

Sun, W., Hattman, S. \& Kool, E. (1997). Interaction of the bacteriophage $\mathrm{Mu}$ transcriptional activator protein, C, with its target site in the mom promoter. J. Mol. Biol. 273, 765-774.

Sun, W., Hattman, S., Fujita, N. \& Ishihama, A. (1998). Activation of bacteriophage $\mathrm{Mu}$ mom transcription by the $C$ protein does not require specific interaction with the carboxy terminal region of the $\alpha$ or $\sigma^{70}$ subunit of Escherichia coli RNA polymerase. J. Bacteriol. 180, 3257-3259.

Wulczyn, F. G. \& Kahmann, R. (1991). Translational stimulation: RNA sequence and structure requirements for binding of Com protein. Cell, 65, 259269.

Edited by J. Karn

(Received 7 April 1998; received in revised form 1 September 1998; accepted 10 September 1998) 